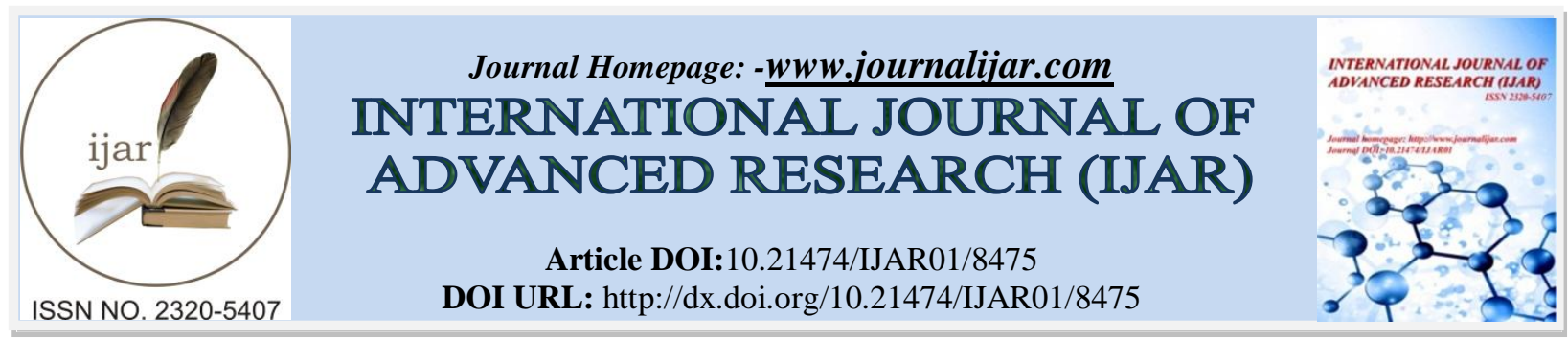

RESEARCH ARTICLE

\title{
RESURGENCE OF NONDESCENT VAGINAL HYSTERECTOMY(NDVH)-THE NEED OF THE HOUR?.
}

\section{Dhanya R Shenoy ${ }^{1}$ and Prameela Menon ${ }^{2}$.}

1. Junior Resident, Department of Obstetrics and Gynaecology, Amala Institute of Medical Sciences, Thrissur, Kerala-680555.

2. Associate Professor, Department of Obstetrics and Gynaecology, Amala Institute of Medical Sciences, Thrissur, Kerala-680555.

\section{Manuscript Info}

\section{Manuscript History}

Received: 02 December 2018

Final Accepted: 04 January 2019

Published: February 2019

Key words:-

Hysterectomy, NDVH, safe.

\section{Abstract}

Background: Hysterectomy is the second most common operation performed by gynaecologist. The motive to try to suit the surgical procedure to modern medicine, which aims at maximum reduction of surgical damage, has led to the rediscovery of vaginal route. Against this background, we are trying to find out if Nondescent Vaginal Hysterectomy(NDVH) has an edge over Total Abdominal Hysterectomy(TAH) for benign conditions of the uterus(size $<14$ weeks).

Method: Prospective cohort study carried out in the Department of Obstetrics and Gynaecology, Amala Institute Of Medical Sciences, Thrissur during 2016-2017. 80 patients requiring hysterectomy for benign gynaecological disorders, uterine size less than 14 weeks was included in the study, the two groups consisting of 40 cases each of NDVH and TAH respectively. The patient, after discussing the pros and cons of both the surgeries with the consultant, herself decided the route of surgery.

Results: Mean operative time was comparable in both NDVH and TAH arms $(98.8 \pm 30.32 \mathrm{mins}$ vs $99.5 \pm 26.69 \mathrm{mins})$. Intraoperative blood loss and postoperative complications like febrile morbidity and wound infection was significantly lesser in NDVH. Pain during postoperative days 1, 2 and 3(using Visual Analog Scale) was also significantly less in NDVH with mean pain score 3.1, 2.9, 2.9 as compared to 5.00, 5.20, 4.80 in TAH group $(\mathrm{p}<0.05)$. Mean hospital stay was also significantly less with NDVH.

Conclusion: As minimally advancing technology continues to be developed and refined, surgeons must choose the safest and best costeffective surgical approach for the patient; and this necessitates the need for resurgence of NDVH.

Copy Right, IJAR, 2019,. All rights reserved.

First Author:- Dr. Prameela Menon.

Address:- Associate Professor, Department of Obstetrics and Gynaecology, Amala Institute of Medical Sciences, Thrissur, Kerala-680555. 


\section{Introduction:-}

Hysterectomy is the second most common operation performed by gynaecologist, next only to caesarean section ${ }^{1}$. Estimates suggest that one in nine women will undergo hysterectomy in their lifetime.

Hysterectomy has undergone many important changes recently. As minimally invasive technology continues to be developed and refined, surgeons must be discerning in choosing the safest, cost-effective surgical approach associated with best outcomes for each individual patient. The motive to try to suit the surgical procedure to modern medicine, which aims at maximum reduction of surgical damage, has led to the rediscovery of vaginal route.

\section{Rationale of the study:-}

Against the background that, theoretically abdominal exploration is likely to be a major surgery than the vaginal exploration; and the complications like paralytic ileus, incisional hernia, infection etc. are likely to be less with vaginal route, we are trying to find out if NDVH has an edge over the traditional TAH for benign conditions of the uterus, size less than 14 weeks. This comparative study analyses the surgical indications, intraoperative complications and clinical outcomes of patients who underwent Non Descent Vaginal Hysterectomy(NDVH) and Total Abdominal Hysterectomy (TAH) with a similar background.

\section{Aim:-}

To find out if NDVH is more safe, efficacious and patient friendly as compared to the traditional TAH for benign conditions of the uterus, size less than 14 weeks

\section{Objectives:-}

1. To compare safety of NDVH versus TAH in terms of intra and postoperative events like duration of surgery, amount of blood loss, intra and postoperative complications.

2. To find out if NDVH is more patient friendly than TAH in terms of postoperative pain and postoperative hospital stay

\section{Materials and Methodology:-}

This prospective cohort study was carried out in the Department of Obstetrics and Gynaecology, Amala Institute Of Medical Sciences, Thrissur from January 2016 to December 2017. Sample size was calculated from the study by Dr. Smritee Virmani, done in Sunder Lal Jain Hospital Delhi during December, $2014^{7}$.

80 patients requiring hysterectomy for benign gynaecological disorders, uterine size less than 14 weeks was included in the study, the two groups consisting of forty cases each of NDVH and TAH respectively. As the number of TAH outnumbered NDVH cases, the very next TAH(with similar patient characteristics) performed after an NDVH was included in the study.

\section{Inclusion criteria:-}

Women undergoing hysterectomy for benign gynaecological disorders, uterine size less than 14 wks during the study period in AIMS, Thrissur.

\section{Exclusion criteria:-}

1. Patients with uterovaginal prolapse

2. Patients with 3 or more prior major abdominal surgeries ( as they are more likely to have intra-abdominal adhesions)

3. Patients with endometriosis

\section{Details of the study:-}

The patient, after discussing the pros and cons of both the surgeries with the consultant, herself decided the route of surgery. All vaginal hysterectomies were performed without laparoscopic assistance and the need for BSO was decided by individual case scenario irrespective of the route of surgery.

Detailed history and examination was followed by the necessary preoperative investigations. All patients were followed up from the day of surgery till they got discharged from the hospital. 


\section{Results:-}

1. The mean age of women included in the study was $45.1 \pm 5.3$ years. There was no significant difference with regard to patient's age, parity or comorbidities in both the groups.

2. Previous abdominal surgery did not influence the type of hysterectomy.

3. Mean operative time was comparable in both NDVH and TAH arms $(98.8 \pm 30.32 \mathrm{mins}$ vs $99.5 \pm 26.69 \mathrm{mins})$.

4. 24 patients $(60 \%)$ in vaginal hysterectomy group underwent volume reduction techniques. $46 \%$ had bisection of uterus and $37 \%$ had bisection with myomectomy and $17 \%$ had myomectomy alone. There was no increase in intraoperative or postoperative morbidity, postoperative pain or duration of hospital stay with use of volume reduction procedures.

5. Technical difficulty was encountered in two cases of vaginal hysterectomy, due to adhesions and the contour of the fibroid expanding anteroposteriorly preventing descent. Conversion of vaginal hysterectomy to abdominal hysterectomy was associated with slightly increased blood loss and operative time.

6. Regarding visceral injuries, as we had only a small set of patients we encountered no significant changes in either of the two groups.

Table 1:-Intraoperative and postoperative complications of surgery in our study

\begin{tabular}{|c|c|c|c|}
\hline & \multicolumn{2}{|l|}{ NDVH/TAH } & \multirow{2}{*}{$\begin{array}{l}\text { P value } \\
\text { (chi square ) }\end{array}$} \\
\hline & $\operatorname{NDVH}(n=40)$ & TAH $(n=40)$ & \\
\hline Primary hemorrhage & 1 & 0 & $0.237^{\$}$ \\
\hline Intraoperative ureteric injury & 0 & 0 & - \\
\hline Intraoperative bowel injury & 0 & 1 & $0.237^{\$}$ \\
\hline Intraoperative bladder injury & 1 & 2 & $0.553^{\$}$ \\
\hline Postoperative urinary retention & 0 & 1 & $0.237^{\$}$ \\
\hline Postoperative febrile morbidity & 2 & 11 & 0.006 \\
\hline Postoperative wound infection & 0 & 6 & $0.003^{\$}$ \\
\hline Paralytic ileus & 0 & 0 & - \\
\hline Urinary tract infection & 1 & 4 & $0.152^{\$}$ \\
\hline Respiratory infection & 0 & 1 & $0.237^{\$}$ \\
\hline Secondary hemorrhage & 0 & 0 & - \\
\hline
\end{tabular}

\$ Fisher exact test

1. Postoperative febrile morbidity and wound infection was greater in patients undergoing TAH as compared to patients undergoing NDVH with statistically significant $p$ value 0.006 and $0.003(<0.05)$ using fisher exact test.

2. Pain during postoperative days 1,2 and 3 were significantly less with vaginal hysterectomy than abdominal hysterectomy when compared using Visual Analog Scale; with mean pain score 3.1, 2.9, 2.9 during day 1,2 and 3 in NDVH as compared to 5.00, 5.20, 4.80 in TAH group respectively.

Chart 1:-Comparing mean of postoperative pain score of NDVH/TAH

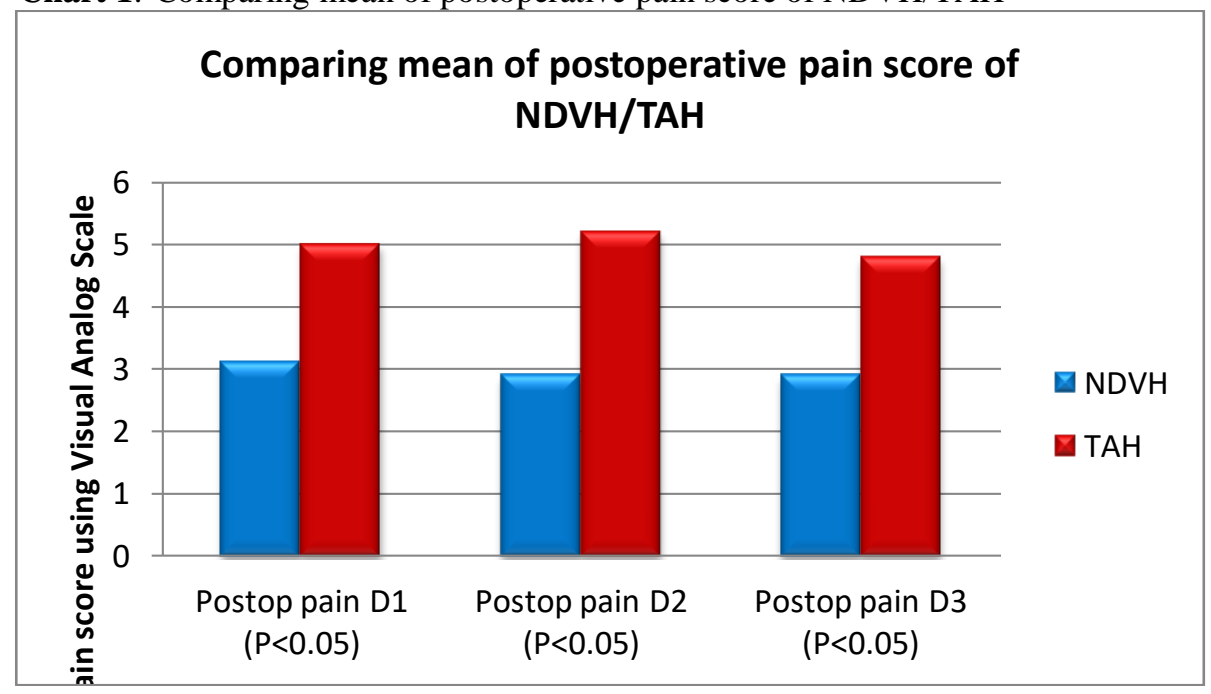


Mean hospital stay was $3.25 \pm 1.08$ days in vaginal hysterectomy group and $5.50 \pm 5.4$ days in abdominal hysterectomy group.

Chart 2:-Comparing days of hospital stay of NDVH and TAH

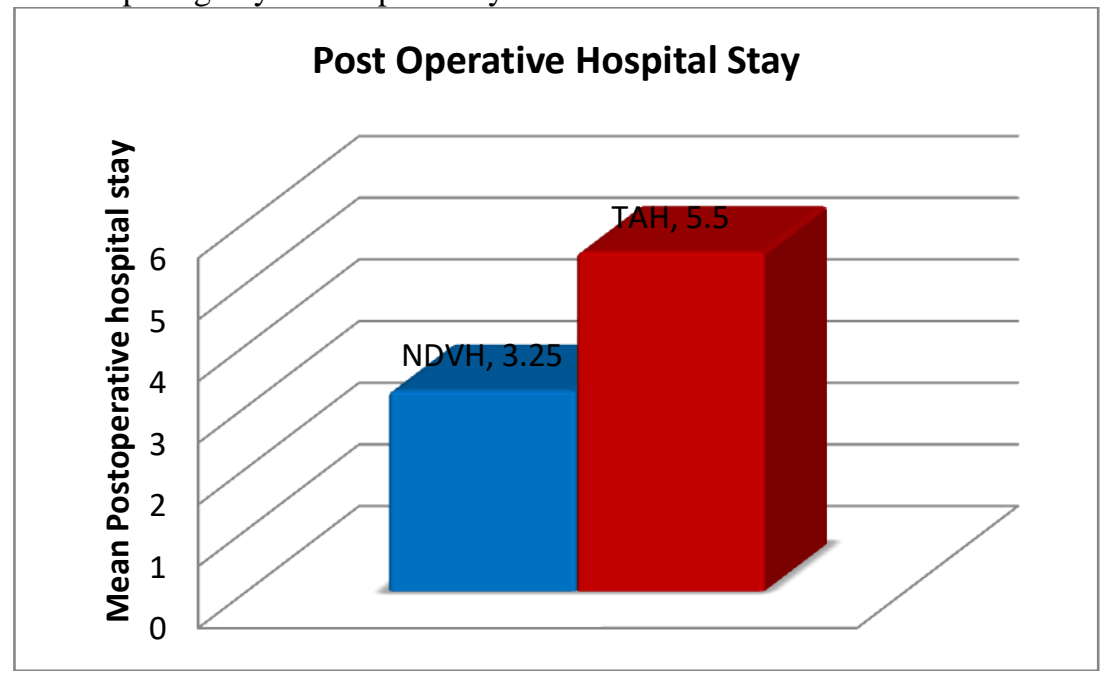

There was no mortality or significant morbidity at 6 weeks follow-up.

\section{Discussion:-}

1. The age of the patients who underwent hysterectomy was comparable to other studies.

2. Though most of the studies reported decreased operative time for NDVH when compared to TAH, our study showed no significant difference between the two groups ${ }^{3-6}$. A similar result was obtained in Harmanli et al (2004) study where the difference in operative time between the vaginal and abdominal procedures (114 vs 137 mins) was not significant. ${ }^{7}$ Maybe with increasing number of surgeries being done vaginally and wIth increasing expertise, the situation might favor NDVH.

Table 2:-Operative time in various studies versus ours

\begin{tabular}{|c|c|c|}
\hline \multirow[t]{2}{*}{ Study } & \multicolumn{2}{|c|}{ Operating time(minutes) } \\
\hline & NDVH & TAH \\
\hline Hoffman (1994) et $\mathrm{al}^{3}$ & 122 & 148 \\
\hline Kovac (2000) et al ${ }^{4}$ & 94 & 118 \\
\hline Hwang(2002)et al ${ }^{5}$ & 74 & 98 \\
\hline Benassi(2002) et al ${ }^{6}$ & 86 & 102 \\
\hline Harmanli(2004) et al ${ }^{7}$ & 114 & 137 \\
\hline Our study & 98 & 99 \\
\hline
\end{tabular}

In our study, the rate of postoperative complications was signifcantly higher in the TAH group as compared to the NDVH group. Febrile morbidity of patients in both arms were comparable with the studies by Gary and Dicker et al(1997), Harris et al (1995) and Nidhi Sharma et al(2015), with significantly higher febrile morbidity in patients undergoing TAH as compared to patients undergoing NDVH. ${ }^{8,9,10}$

Table 3:-Febrile morbidity in various studies and ours.

\begin{tabular}{|c|c|c|}
\hline \multirow[t]{2}{*}{ Study } & \multicolumn{2}{|c|}{ Febrile morbidity rate $(\%)$} \\
\hline & NDVH & TAH \\
\hline Kovac (2000)et al ${ }^{4}$ & 0.8 & 4 \\
\hline Benassi(2002) et al $^{6}$ & 16.5 & 30.5 \\
\hline Harmanli(2004) et $\mathrm{al}^{7}$ & 20.5 & 14 \\
\hline Our study & 5 & 27.5 \\
\hline
\end{tabular}


Similarly, postoperative wound infection occurred only in TAH group with statistically significant $\mathrm{p}$ value 0.003 $(<0.05)$ using fisher exact test. This was similar to the studies by Gary and Dicker et al(1997), Harris et al (1995) and Nidhi Sharma et al(2015) ${ }^{8,9,10}$ There was no case of vault infection in our study. Postoperative urinary tract infection and respiratory infection rates were comparable within the two groups, $\mathrm{p}=0.152$ and $\mathrm{p}=0.237(>0.05)$ using fisher exact test.

Table 4:-Comparing postoperative infection rates in various studies and ours

\begin{tabular}{|l|l|l|l|l|l|l|l|l|}
\hline & \multicolumn{2}{|l|}{$\begin{array}{l}\text { Gary\&Dicker } \\
(1997)^{8}\end{array}$} & \multicolumn{2}{l|}{$\begin{array}{l}\text { Harris WJ } \\
(1995)^{9}\end{array}$} & \multicolumn{2}{l|}{$\begin{array}{l}\text { Nidhi Sharma } \\
(2015)^{10}\end{array}$} & $\begin{array}{l}\text { Our study } \\
(2017)\end{array}$ & \\
\hline & TAH & NDVH & TAH & NDVH & TAH & NDVH & TAH & NDVH \\
\hline No of patients & 1283 & 568 & 1184 & 530 & 90 & 90 & 40 & 40 \\
\hline Febrile morbidity & $16.8 \%$ & $7.2 \%$ & $10-20 \%$ & $0.5-8 \%$ & $4.4 \%$ & 0 & $27.5 \%$ & $15 \%$ \\
\hline Wound infection & $8.1 \%$ & $2.1 \%$ & $\begin{array}{l}6.6- \\
25 \%\end{array}$ & $\begin{array}{l}3.9- \\
10 \%\end{array}$ & $13.3 \%$ & $3.3 \%$ & 15 & 0 \\
\hline Vault infection & $1.3 \%$ & $1.2 \%$ & $\begin{array}{l}3.2- \\
10 \%\end{array}$ & $\begin{array}{l}3.9- \\
10 \%\end{array}$ & 0 & 0 & 0 & 0 \\
\hline $\begin{array}{l}\text { Urinary tract } \\
\text { infection }\end{array}$ & $7 \%$ & $3.4 \%$ & $1.1-5 \%$ & $1.7-5 \%$ & $4.4 \%$ & $1.1 \%$ & $10 \%$ & $2.5 \%$ \\
\hline $\begin{array}{l}\text { Respiratory tract } \\
\text { infection }\end{array}$ & $0.4 \%$ & $0.4 \%$ & $\begin{array}{l}0.4- \\
2.6 \%\end{array}$ & $0.3-2 \%$ & 0 & 0 & 0 & 0 \\
\hline
\end{tabular}

Regarding the effect of volume reduction procedures in ndvh, there was no statistical difference between intra/postoperative complications, postoperative pain or duration of hospital stay when volume reduction procedures were undertaken. However there was significant increase in the operative time with the use of volume reduction procedures in $\mathrm{NDVH} p=0.03(<0.05)$, probably because these procedures were adopted only when there was difficulty in delivering out the specimen due to comparatively larger size uterus.

In our study, postoperative pain was significantly decreased during day 1, 2 and 3 following NDVH as compared to TAH. This finding was correlating with the study done by Rathinthra Nath Ray, $2015^{11}$ and Shivan et al, $2017^{12}$ where they found day3 mean pain score in NDVH as 2.88 and 1.8 and that of TAH as 6.48 and 2.88; with the difference in the pain rating score between the two groups to be very much statistically significant with a $\mathrm{P}$ value $<0.05{ }^{11}$

Table 5:-Postoperative pain score in ours versus studies

\begin{tabular}{|l|l|l|}
\hline \multirow{2}{*}{ Study } & \multicolumn{2}{|l|}{ Postoperative pain score Day 3 } \\
\cline { 2 - 3 } & NDVH & TAH \\
\hline Rathinthranath Ray et al (2015) $^{11}$ & 2.8 & 6.5 \\
\hline Shivani (2017) et al & 12 & 2.9 \\
\hline Our study & 1.8 & 4.8 \\
\hline
\end{tabular}

Postoperative hospital stay was significantly more for abdominal hysterectomy patients as inferred from the present study. This was comparable to previous studies done by Hoffman et al $(1994)^{3}$, Kovac et al(2000) ${ }^{4}$ and Miskry et al $(2003)^{13}$ The Cochrane data base study also reports a shorter hospital stay and earlier return to normal activities for Vaginal Hysterectomy.

Table 6:-Comparing hospital stay in various studies and ours

\begin{tabular}{|l|l|l|}
\hline \multirow{2}{*}{ Study } & Hospital stay (days) \\
\cline { 2 - 3 } & NDVH & TAH \\
\hline Hoffman et al $(1994)^{3}$ & 3.6 & 5.0 \\
\hline Kovac $(2000)^{4}$ & 2.8 & 3.9 \\
\hline Miskry et al $(2003)^{13}$ & 3 & 5 \\
\hline Our study & 3.3 & 5.5 \\
\hline
\end{tabular}




\section{The benefits of NDVH over TAH as observed in our study are:-}

1. Scar less surgery.

2. Decrease in the blood loss.

3. Decrease in postoperative febrile morbidity.

4. Decrease in postoperative wound infection.

5. Decrease in postoperative pain.

6. Decrease in the hospital stay and earlier return to normal activities.

This justifies Pratt's statement in 1976 that " if a uterus is to be removed it is best removed vaginally, other things being equal."

\section{Conclusion:-}

NDVH has proved to be more safe, efficacious and patient friendly with fewer intraoperative and postoperative complications, reduced hospital stay and early recovery as compared to the traditional TAH for benign conditions of the uterus, size less than 14 weeks. With expertise, NDVH can be succesfully accomplished even in challenging situations such as previous pelvic surgery, nulliparity and increasing uterine size.

As minimally advancing technology continues to be developed and refined, surgeons must choose the safest and best cost-effective surgical approach for the patient; and this necessitates the need for resurgence of NDVH.

\section{References:-}

1. Singh KC, Barman SD, Rinku Sengupta. Choice of hysterectomy for benign disease, Department of Obstetrics and Gynaecology, University College of Medical Sciences, Delhi J. Obstet. Gynecol 2004; vol:54, July/August 2004

2. Smriti Virmani et al. Surgical trends in hysterectomy- a comparative analysis. Indian Journal of Applied Research 2014; vol:4, December 2014

3. Hoffman MS, Decesare S and Kalter C. Abdominal hysterectomy versus transvaginal morcellation for the removal of enlarged uteri, Am J Obstet Gynecol 1994;171:309-15.

4. Kovac SR. Hysterectomy Outcomes in Patients with Similar Indications. Obstet Gynecol 2000;95:787-93.

5. Hwang JL, Seow KM, Tsai YL, Huang LW, Hsieh BC and Lee C. Comparative study of vaginal, laparoscopically assisted vaginal and abdominal hysterectomies for uterine myoma larger than $6 \mathrm{~cm}$ in diameter or uterus weighing at least $450 \mathrm{~g}$; a prospective randomized study. Acta Obstet Gynecol Scand 2002;81(22):1132-8.

6. L. Benassi, MD, T. Rossi, MD, C.T. Kaihura, MD, L. Ricci, MD, L. Bedocchi, MD, B. Galanti, MD, and E. Vadora, MD Abdominal or vaginal hysterectomy for enlarged uteri:A randomized clinical trial .Am J Obstet Gynecol 2002;187:1561-5.

7. Harmanli OH, Gentzler CK, Byun S, Dandolu V, and Grody MHT. A comparison of abdominal and vaginal hysterectomy for the large uterus. Int J Gynecol Obstet 2004;87(1):19-23.

8. Garry R. Comparison of hysterectomy techniques and cost benefit analysis. Clin Obstet Gynaecol.1997; 11(1) :137-148

9. Harris W. Early complications of abdominal and vaginal hysterectomy. Obstet Gynaecol Suev 1995;50:795

10. Sharma Nidhi. Comparative analysis of trial vaginal hysterectomy and abdominal hysterectomy. Journal of Evolution of Medical and Dental Sciences. 2015;Vol.4 Issue95,NOV.26; 16052-16056.

11. Meltomaa SS, Makinen JI, Taalikka MO and Helenius HY. One year cohort of abdominal, vaginal, and laparoscopic hysterectomies: complications and subjective outcomes. J Am Coll Surg 1999;189(4):389-9

12. Abrol Shivani, Rashid S, Jabeen F, Kaul S. Comparative analysis of non-descent vaginal hysterectomy versus total abdominal hysterectomy in benign uterine disorders. Int J Reprod Contracept ObstetGynecol2017;6:846-9.

13. Miskry $\mathrm{T}$ and Magos A. Randomized, prospective, double blind comparison of abdominal and vaginal hysterectomy in women without uterovaginal prolapse. Acta Obstet Gynecol Scand 2003;82(4):351-8. 